\title{
Roteiro de Jardins Rurais em Victor Graeff, RS, Brasil: Jardinistas por vocação! Ou ... a metamorfose das agricultoras ${ }^{(1)}$
}

\author{
CLÁUDIA PETRY(2)
}

\begin{abstract}
RESUMO
Nos anos 1970, nesta região gaúcha houve considerável êxodo rural e movimento de migração em direção ao norte do Brasil. A erosão altamente destrutiva obrigou à adoção de algumas ações estatais emergenciais, como o manejo integrado de microbacias locais. Na crise, o que predetermina uma comunidade rural permanecer no local de origem familiar? E para se organizar para ser visitada? Como um técnico pode auxiliar nesta organização? Como o paisagismo pode auxiliar? Algumas respostas à estas questões serão abordadas neste estudo de caso sobre o roteiro turístico dos jardins rurais de Victor Graeff, RS, Brasil. Será apresentado um breve histórico desse processo com quase quinze anos desde sua concepção, alguns técnicos envolvidos, a infra-estrutura básica, as dez agriculturas engajadas no processo inicial e as atuais sete associadas, assim como seus anseios de bem-estar e de qualidade de vida expressos nessas suas criações particulares. Preliminarmente, constata-se que para bem recepcionar o olhar exterior (o turista) é necessário uma elevada autoestima, e o constante cultivo desta, além dos cuidados com a aparência estética dos jardins. Além disso, o técnico deve garantir a manifestação das motivações individuais, pois sem estas, não há um processo coletivo de turismo com sucesso, valorizando o ineditismo e o localismo. E vice e versa, poder se expressar probamente alimenta corretamente a autoestima. A terceira constatação é que se trata de um processo, caminho a ser percorrido e sendo assim, há constantes reavaliações e retomada de decisões. É artifício e processo dinâmico, como a própria vida. Em cada civilização afloram expressões de uma cultura jardinista e paisagista nos jardins privados, mesmo os periurbanos e rurais, onde se opõem e se complementam o artifício e o natural, enriquecendo de sentido o imaginário da vida cotidiana. O caso destas habitantes paisagistas, jardinistas rurais, nos demonstra que o principal objetivo foi alcançado: o de permanecer na zona rural com qualidade de vida, com distinção e orgulho por sentirem-se parte de um modelo de vida por elas construído, digno de ser visitado.

Palavras-chave: habitante paisagista, paisagismo, patrimônio verde, organização associativa, turismo rural.
\end{abstract}

\begin{abstract}
Rural Gardens Tour in Victor Graeff, RS, Brazil: Called to be Gardeners! Or ... the metamorphosis of farming women
\end{abstract}

In the 1970s in this micro-region of Rio Grande do Sul, Brazil, there was considerable rural flight and migratory movement to the north of Brazil. Highly destructive erosion required the adoption of some emergency activities on the part of the state, such as integrated management of local micro watersheds. In the crisis, what pre-disposes a rural community to remain in the location of family origin? And how does one prepare to be visited? How can a technician assist in this organization? How can landscaping help? Some answers to these questions will be taken up in this case study regarding the rural garden tour route of Victor Graeff, RS, Brazil. The background of this process, now nearly fifteen years from the time of conception, will be presented, as well as some techniques involved, the basic infrastructure, the ten farm women involved in the initial process and the current seven associates, and their desires for well-being and quality of life expressed in their private creations. To begin with, it is seen that to receive outside attention (the tourist), high self-esteem is necessary, and constant cultivation of it, beyond caring for the aesthetic appearance of the gardens. In addition, the technician must ensure manifestation of individual motivations because, without them, there is no successful collective tourist process, valuing that which has not been seen before and local flavor. And vice versa, being able to express oneself with dignity feeds self esteem in a healthy manner. The third observation is that this is a process, a path to be traveled and, thus, there are constant re-assessments and review of decisions. It is a skill and a dynamic process, just like life itself. In each civilization, expressions of a gardening and landscaping culture bloom in private gardens, even those in periurban and rural areas, where what is crafted and what is natural contrast and complement each other, bestowing meaning on the conceptual dimension of daily life. The example of these landscaping residents, rural gardeners, shows us that the main goal was reached - that of remaining in the rural area with quality of life, with distinction and pride, through feeling part of a model of life which they have built, worthy of a visit.

Keywords: landscaping resident, landscaping, green heritage, association, rural tourism

\footnotetext{
(1) Recebido em 10 de maio de 2013 e aceito para publicação em 30 junho de 2013 .

(2) Enga.Agra., Doutora em Geografia (Université Paris I Panthéon La Sorbonne), Pós-doutoranda Bolsista CNPq em Agroecologia no Laboratório Ruralités da Université de Poitiers (2012-2013), professora titular de paisagismo,floricultura e plantas medicinais da Universidade de Passo Fundo (UPF), docente do Programa de Pós-Graduação em Agronomia (PPGAGRO) e consultora extensionista do Centro de Ciências e Tecnologias Ambientais (CCTAM) da UPF.
} 


\section{INTRODUÇÃO}

Para compreender o global, é importante desvelar exemplos locais. Isso se aplica sobretudo à paisagem. São os municípios que nos elucidam detalhes de retalhos de território. Victor Graefffica numa região de desenvolvimento das granjas, próxima à Passo Fundo, cidade de porte médio situada no planalto médio gaúcho, esta última considerada já há mais de 20 anos como cidade-núcleo, moderna e com boa infraestrutura (PEBAYLE, 1989). É na zona rural que ela apresenta numerosas microrregiões com uma produção diversificada, onde começam a ser produzidos produtos coloniais oriundos da produção orgânica. A seguir, vamos explorar mais os olhares sobre estas paisagens. E depois os fazeres.

Na cidade de Victor Graeff, os motivos paisagísticos de origem européia são a igreja luterana com sua torre gótica e o conjunto vegetal (tombado patrimônio estadual) de topiarias na praça Tancredo Neves com uso de espécies européias. Foi nessa praça que o jardineiro Fridolino Selmiro Schmidt vinha criando desde 1989 belos exemplares nas formas animais, humanas e geométricas. É a partir de caminhos entre as sebes podadas que se vê o campanário neogótico tendo como fundo a paisagem rural bordada de trilogia agrária (Pastagem + floresta + lavoura). Mesmo se ainda não tem hotel na cidade, já existe demanda localizada. Há uma feira agrícola (Expodireto) que ocorre em março na cidade vizinha de Não-me-Toque $(15 \mathrm{~km}$ de distância) e que empresta seus visitantes nos finais de tarde da feira à esta pequena Victor Graeff oferecer-lhes na praça com topiarias o prato típico "cuca com lingüiça". A tradição continua e a paisagem é mais valorizada quando há a degustação junto.

A primeira identidade nacional brasileira nasceu da paisagem nacional natural. Os símbolos nacionais todos exploram a riqueza da natureza. No século 20 , houve uma valorização dos produtos nacionais e de recursos primários o que levou à uma superexploração em direção ao norte do País. Se naquele século, houve um olhar fragmentado para o Brasil, enfim, no século 21, o olhar é ampliado para a totalidade dos grandes ecossistemas. Estes começam enfim a serem mais bem compreendidos e apreciados, tornando a duras penas o meio-ambiente mais valorizado como prêmio e patrimônio da paisagem brasileira. A partir daquele primeiro projeto de paisagem nacional, mudou a necessidade de garantir o lugar à ética nesses novos olhares e manejo, com o objetivo do desenvolvimento sustentável (PETRY, 2003). Victor Graeff sofreu desse fenômeno migratório no inicio dos anos 1970, sobretudo em função da grande degradação do solo agrícola na região. Esta erosão altamente destrutiva obrigou à adoção de algumas ações estatais emergenciais, como a criação das primeiras microbacias pilotos do estado gaúcho, propondo o manejo local integrado destas.

No início da colonização, o olhar exterior (o olhar do outro), é o dos naturalistas descrevendo o paraíso como uma coleção de natureza. Hoje o naturalista é o que coleciona plantas, que cultiva uma horta diversificada, que preserva diversos habitats. $\mathrm{O}$ olhar interior, o do habitante, começa com este projeto nacionalista da paisagem grandezanatureza (récitos românticos do século 19, redigidos pelos habitantes residentes), e os regionalismos destes precursores locais, mas continua com o olhar do eterno "pioneiro". O olhar do pioneiro é aquele olhar fragmentado, visando melhor explorar os recursos na ocupação dos espaços. Foi muito elogiado no início da colonização sulina, hoje ele é mais autocrítico, de um colonizado em busca de identidade nestas paisagens, sem ser um nacionalista exibido. E isso se passa com ele se reconhecendo parte integrante da natureza, ou ao menos do que restou dela: o meioambiente. Como se perdurasse uma batalha entre os dois, o naturalista e o pioneiro. Mas será a resolução de forma dialética do pioneiro versus naturalista (PETRY, 2003) que permitirá aos brasileiros encontrar sua síntese de manejo do território e representações brasileiras nesta complexidade de paisagens. Se estas soluções ainda não são viáveis em todo o país, entretanto respostas adaptadas a uma pequena escala de influência começam a aparecer localmente. E normalmente eles surgem ligados á preservação do meioambiente. O caso das habitantes paisagistas de Victor Graeff é um deles.

A região tem tradição de roteiros turísticos (Rota das terras) e como prerrogativas estas agricultoras (a maioria de origem européia) queriam ter mais motivos para ali permanecerem satisfeitas com seu estilo de vida. Já se sentiam engajadas no processo de criar seus jardins, peculiares e diferentes um do outro. Mas ao se organizarem isso se solidificou. Sempre contaram com o apoio do governo (Prefeitura, Emater, Senar) e da nossa universidade, que é comunitária. Enquanto instituição de ensino e pesquisa, a Universidade buscou proporcionar treinamentos extensionistas para acadêmicas da agronomia, interessadas em botânica e paisagismo. Assim também auxiliar a registrar a diversidade do patrimônio vegetal do jardim rural notável de dona Delci Gnich (considerada a mãe dos jardins rurais, por ser a precursora) e de devolver o registro do levantamento florístico das topiarias da Praça Tancredo Neves à prefeitura do município. Ao trazer nosso conhecimento cientifico, sempre tentamos considerar que o habitante paisagista deverá se emancipar dos agentes externos, e em sua autonomia continuar recriando sua relação amorosa com a paisagem de onde mora.

Então sobre a autossuficiência do habitante paisagista, nossa idéia principal a ser apresentada aqui é indicar e questionar possíveis atitudes e posturas dos técnicos/ profissionais para garantir em suas assessorias a escala de ser humano autônomo do habitante paisagista. São estas minhas sugestões para a postura do técnico: a) Ser completamente responsável por suas indicações, acreditar no que faz e fazer pelo melhor (implica em falhar o menos possível, lembrando sempre que o habitante não vai poder mudar de local, se seu aviso técnico não funcionar); b) Motivar sempre; c) Tentar buscar a imparcialidade administrativa, sem agir impondo decisões partidárias, conforme mudam administrações e cargos inerentes.

E ainda, numa situação de crise, o que predetermina uma comunidade rural permanecer no local de origem familiar? E para se organizar para ser visitada? Como um técnico pode auxiliar nesta organização? Como o paisagismo pode auxiliar? Algumas respostas à estas questões serão enfocadas neste estudo de caso sobre o roteiro turístico dos jardins rurais de Victor Graeff, RS, Brasil. 


\section{MATERIAL E MÉTODOS}

Em 1998, a UPF participou, através do Centro de Ciências e Tecnologias Ambientais (CCTAM) do projeto nacional do Ministério do Meio Ambiente "Adote uma Bacia". O maior estímulo veio da arquiteta Maria do Carmo Zinato, uma das coordenadoras nacionais do Projeto. Tratava-se de ações de formação com palestras e dias de campo para conscientizar sobre a importância da água na bacia hidrográfica. Parecia difícil encaixar o paisagismo como uma ferramenta para agricultores num edital tão específico. Daí a importância da técnica acima insistir para nos engajarmos enquanto instituição. Ela percebia a fluidez da interdisciplinaridade, que nós ainda não visualizávamos neste caso específico.

Uma das agricultoras (dona Delci Gnich) ao participar da primeira palestra de paisagismo se sentiu motivada e saiu decidida para praticar o paisagismo na sua propriedade. Em 19/10/1999, já aparece dona Delci como palestrante do tema "floricultura" no evento Seminário de Turismo Rural em Ibirubá, promovido pela Emater e Prefeitura locais, na mesa redonda "Experiências de turismo no Meio Rural em Victor Graeff'(1). E assim dona Delci continuou a caminhada buscando parceiras para criar uma rota de jardins rurais. Contando com o apoio da Prefeitura e a Emater de Victor Graeff, foi esta agricultora a precursora da rota turística dos jardins rurais.

Em 2004 houve o primeiro treinamento do Senar, com a engenheira agrônoma Sandra Rigo, objetivando criar jardins com múltiplos setores e usos. Mesmo se a idéia inicial foi propor um plano básico idêntico elencado para todas as agricultoras (com mesmas atividades e usos no jardim:, estares, plantas medicinais, horta, fonte, tapete verde, cactáceas vasos, forrações alternando com texturas minerais) cada um foi se diferenciando e se tornando único.

Segundo KOFF e GOBBI (2012), extensionistas da Emater, o turismo rural de jardins em Victor Graeff acontece oficialmente desde 2005, a partir de um concurso de jardins da prefeitura e de um curso de jardinagem e paisagismo. Em 17 de novembro de 2006 é divulgada no jornal local a excursão aos jardins organizada pela administração municipal para seus servidores conhecerem o roteiro “(...) é engraçado como saímos para fazer turismo fora antes mesmo de conhecermos nosso município $(\ldots)^{\prime(2)}$ e ao fazer mais gente conhecer, buscavam ajuda na divulgação, demonstrando o empenho local para o roteiro dar certo (O MENSAGEIRO, 2006).

A universidade voltou então para auxiliar, através do grupo de paisagismo existente. A partir de uma visita da turma de paisagismo, duas acadêmicas Jucelâine Vanin e Francieli Mariani se colocaram a disposição para efetuar o levantamento florístico do jardim da dona Delci, permanecendo duas semanas na propriedade, alojadas pela família, sendo uma em dezembro de 2006 e a segunda em fevereiro de 2007. Na primeira visita elas já coletaram material vegetal e fotos destes para identificação na UPF, mas a maioria da identificação foi in loco, através de bibliografia específica desta pequena equipe. Foi uma pesquisa qualitativa.

E enfim, em 2007 foi criada oficialmente a Associação municipal de turismo Caminho das Topiarias, flores e aromas. No primeiro folder da associação aparece o roteiro oficial na forma da lista com fotos dos 10 jardins e dos dois pontos turísticos (a praça com topiaria e o balneário).

Na Praça Tancredo Neves, a arte topiaria foi iniciada pelo senhor Fridolino Schmidt, no final dos anos 1980, mas ainda não havia um registro desse patrimônio, embora a praça seja tombada como patrimônio estadual. Em julho de 2007, as acadêmicas de agronomia Ana Trentin e Lidiane Malaguti, por sua vez, realizaram o levantamento florístico com a localização das figuras esculpidas em cipreste (Cupressus sempervirens), transferindo esse levantamento para uma prancha em tamanho A2 em abril de 2008. Uma cópia impressa colorida desse levantamento foi entregue ao prefeito de Victor Graeff, durante a visita dos acadêmicos de paisagismo no final do primeiro semestre de 2008.

Após as eleições municipais de 2008, houve um descompasso temporário no processo coletivo dos jardins, por haver ajustes na mudança de governo e das prioridades. Mesmo nós, técnicos da universidade, não levamos mais na época excursões com alunos, o que foi lamentável de nossa parte. Enfim, foi uma fase de adaptação aos novos tempos. E as jardinistas se mantiveram unidas embora os percalços.

Em abril de 2012, na última visita que fizemos com os alunos da UPF, visitamos então os atuais sete jardins e fomos honrosamente convidados para conhecer o novo jardim da dona Delci, agora na área urbana do município vizinho de Ernestina.

Em junho de 2012, Jucelaine Vanin ${ }^{(3)}$, agora como instrutora do Senar proporcionou mais um treinamento de três dias com as jardinistas. Através de uma pesquisa no arquivo pessoal de dona Delci (notícias de jornal, folders, ofícios...) houve a possibilidade de melhor compreender as etapas cronológicas do roteiro. Lamentável que nos arquivos aparece os ofícios, algumas falas em noticias de jornal, mas faltam relatórios e atas de reuniões. Não é a ela a função de tê-los. Mas eles deveriam existir. Estas informações tão importantes ainda são parciais. Como técnicos todos deveriam atentar para eles, pois formam os arquivos históricos de amanhã.

Em 19 de agosto de 2012, realizei uma entrevista coletiva com dona Delci e com Rosmari Munerolli, a extensionista da Emater que estava em Victor Graeff em 1998, buscando resgatar oralmente as impressões das duas sobres as origens das ações destas habitantes paisagistas.

\footnotetext{
(1) Onde ainda palestraram o senhor Fridolino Schmidt, que realizava as topiarias na praça e Valdir Krombauer, piscicultor e proprietário do Balneário de mesmo nome.

${ }^{(2)} \mathrm{Na}$ época, Dirigente de turismo Mauri Schumann, 2006.

(3) Acadêmica da agronomia, que catalogou as plantas do jardim de dona Delci em 2006-2007;
} 


\section{RESULTADOS E DISCUSSÃO}

\section{Breve histórico da construção destes habitantes paisagistas}

Em 2007, o levantamento florístico do jardim de Delci Gnich resultou em 24 pranchas de croquis, localizando na sede da propriedade as 598 espécies identificadas numa tabela de memorial botânico (com códigos, nomes científico e popular), tanto arbóreas, quanto arbustivas e forrações. Houveram espécies não identificadas. Esse material foi devolvido na forma de um portfólio para a agricultora em 10 de maio de 2007, na visita técnica dos alunos de Paisagismo daquele semestre. Essa informação já consta no primeiro folder do roteiro em 2007 ao se referir ao jardim de dona Delci:

“[...] há algo de magia e poesia nesta propriedade. O jardim, as flores, o aroma, o canto dos pássaros, o murmurinho das águas... A história de dona Delci é inspiradora às pessoas que apreciam qualidade de vida, juntamente com a grandeza e a beleza que este jardim pode proporcionar. Aqui são encontradas mais de 700 espécies de flores, folhagens e arbustos catalogados pelo curso de agronomia da Universidade de Passo Fundo".

Em 2008, o levantamento floristico completo do conjunto de topiarias da Praça Tancredo Neves (com a respectiva localização das figuras topiadas) foi aplicado numa prancha A2. Nela, estão localizados os 656 ciprestes utilizados para criar na época cerca de 150 variadas representações, de dinossauros a anjos, passando por túneis e cenas típicas regionais, como o agricultor com a junta de bois arando e o casal dançando ao lado da banda de música. Mais abaixo, apresentamos algumas explicações pessoais do artista horticultor criador das topiarias originais.

Essa riqueza produzida pelos habitantes paisagistas pode ser resumida na lista dos 10 jardins e dos dois pontos turísticos (a praça e o balneário) que começaram o roteiro oficial em 2005:

1) IONE e NAIR (sogra e nora) $=$ com o apoio dos maridos: horta magnífica, o hortus puro, medicinais, plantas raras, objetos diferentes, a vossoroca escondida, mas ainda existente, o lanche caseiro delicioso. É impressionante a diversidade de plantas comestíveis e medicinais. Foi possível resgatar várias espécies de flores também.

2) SIRLEI com suas belas plantas e o mundo encantado de seu esposo: tem espalhadas pelo jardim esculturas e cerâmicas feitas por ele. Tem uma representação de uma cena medieval que ele tirou o molde em gesso num restaurante na Espanha e trouxe o molde no colo, no avião. Ele construiu cercas com estilo próprio. Sirlei coleciona muitas espécies diferentes em cada setor (cactáceas e bromélias). Com eles conheci a cucurbitácea Kino e trouxe uma muda de avelós. Tem uma placa indicando a direção pra ir pra Alemanha, ela é logo ali diz a seta anunciando 11 mil km ao nordeste, parodiando "O Brasil não é longe daqui", o mesmo título de uma velha canção alemã do século 19 (SÜSSEKIND, 1990).

3) DIVA do capricho na terra emprestada: o barranco + quiosque + fonte + roda de moinho + potes com plantas espalhados em todo canto (coleção incrível de prímulas)
+ espécies diferentes e rústicas e cheirosas + o desejo de participar que o marido apóia firmemente. A delicadeza dessa mulher numa casa aconchegante com tantos vasos espalhados faz a paisagem ficar ainda mais suave e chamativa.

4) DELCI, irmã da DIVA: seu grande jardim doou terreno para a construção da casa do filho. Seu pomar virou uma rica floresta de frutíferas nativas. Nos barrancos pingam gotas do rabo-de-gato constrastando com a sempreverde variegata. A pequena fonte, as cannas escondem o estábulo, o guabiju maravilhoso convida para sentar em sua sombra, a coleção de gérberas é generosa e esplêndida; o chimarrão nem se fala.

5) MÁRCIA e seu jardim impressionista: lago + carroça + cactáceas no sub-bosque + potinhos por tudo (assim ela começou para vencer a tristeza de ter saído da cidade) + horta + hoje um extenso gramado e grande quiosque pra receber confortavelmente as pessoas. A antiga briga de esconder vossorocas na rua de acesso acabou... Pois a vizinhança toda concorda agora que não querem mais ter vossorocas.

6) DELCI, a mãe dos jardins e mãe da ANEGRID floricultora e paisagista: coleção de plantas original (agora reapropriado pela Anegrid: estufas + jardim mais prático para cuidar + casa de bonecas + família participativa. O que para ela é seu maior patrimônio)

7) REJANE e seu "tapete verde" (tapis vert) na exroça de mandioca ("fica mais fácil cortar a grama agora que capinar antes a mandioca", fala do esposo orgulhoso do jardim). Eles têm no jardim a fonte murmurante + varandas + horta + herbáceas de sombra (um belo exemplar de xaxim) + porão charmoso + matódromo (lugar para matear ou tomar chimarrão) que virou quiosque protegido para os rituais de café colonial no final da tarde, que são no final de visita... deliciosos... a comida é maravilhosa. A acolhida, nem se fala.

8) ANEGRID floricultora no seu antigo jardim em terra emprestada: tinha estufa, com o passeio entre os setores de plantas. Ela fazia questão de mostrar o local que não nascia mais nenhuma planta, nem invasora (era onde o trator parava e ali pingava o herbicida). Nas visitas, tinha a pausa para dar mamadeira para Luane ou para atender um telefonema solicitando mudas. Daqui eles foram defitivamente morar na terra da família dela, assumindo seu lugar no antigo jardim que dona Delci havia criado.

9) ROVENA: jardim para o filho com necessidades especiais... uma pérola esse jardim com acessibilidade, dedicado ao filho paraplégico do casal... cactos, liliáceas, perenes e vivazes, muita rusticidade e baixa manutenção. A família se retirou do Roteiro, entre outras razões, por não poder mais permanecer em casa durante as visitas. E talvez também porque o filho não está mais com eles...

10) ADRIANA e seu jardim rural: Nele, tinha a roça chegando até na beira do jardim, tinha o rio que sonorizava o passeio na mata ciliar, tinha as filhas lindas (que os estudantes de agronomia em todas as visitas queriam pedir a mão em namoro...). Tinha... não tem mais, pois saiu do roteiro após eleger-se vereadora.

11) No início da visita, passeio guiado na praça de topiarias de Victor Graeff e a casa do artesão. Pausa para fotos memoráveis. 
12) No meio-dia, o almoço no balneário Krombauer: plantas rústicas, amplos gramados, piscinas, açudes e cabanas de uso maior no verão.

Em abril de 2012, na última excursão com acadêmicos da UPF, visitamos então os atuais sete jardins (os sete primeiros acima, sendo que Anegrid assumiu o local do antigo jardim de dona Delci) e fomos convidados para conhecer o novo jardim da dona Delci (a mãe dos jardins) na área urbana de Ernestina, município vizinho.

\section{A história de um sonho de um habitante paisagista "Mãos de tesoura"(4)}

Senhor Fridolino Schmitt é um agricultor aposentado de Victor Graeff, com muitas habilidades, aprendeu a podar com os padres maristas e nos anos 60, percebeu esta tendência de haver topiaria nas praças municipais (bonecos em Tapera e Cruz Alta), mas conforme o tempo passava, lamentava que esta tradição estivesse se perdendo. Então, costumava comentar que a praça de Victor poderia ser mais bonita se recebesse trabalhos de jardinagem e de topiaria. Até que um amigo dele ao se tornar prefeito de Victor Graeff, de tanto escutá-lo e por conhecer sua criatividade e boa índole, desafiou-o para transformar a praça, convidando-o a ser jardineiro da prefeitura. Então, com 53 anos, em 1989 seu Fredolino deixou a propriedade rural para o filho e o genro e permaneceu na sede, com seu ofício de jardineiro. Hoje, seu trabalho como topiarista é reconhecido como de primeiro escalão, mesmo a nível internacional. Na Ecole de Paysage de Versailles, o historiador Michel Racine comentou em 2000, que é muito difícil este tipo de poda e que ele mesmo nunca tinha visto nada igual. Que maravilha descobrir um dom aos 53 anos, na chamada terceira idade, a mais doce idade: a idade da experiência aliada à memória cultural e à qualidade de vida.

Ele foi aprendendo na prática. No seu empirismo e sempre com cipreste comum (por causa dos invernos rigorosos na região, é a espécie mais recomendada) começou com uma peça e outra, e foi evoluindo nas formas criadas. Além do "murinho", tem o cipreste "quiosque" onde se instala um banco dentro dele. Daí veio a forma "chapeuzinho", até que deixou um broto superior e desenhou... um leão ! Depois macacos, cavalos, e assim prosseguiu. Garante que aprendeu com as árvores, com os "recados" delas ... "se ela aceitava essa poda (não sofria, não morria...) eu continuava evoluindo as formas... senão eu parava ali". Aprendeu com o erro e acerto, inclusive em 2003 houve um sério ataque de cochonilhas na praça. Foram técnicos da Embrapa Floresta que recomendaram o produto e o manejo adequado para tanta poda, "sim, a poda enfraquece, a partir desse recado além do tratamento fitossanitario, começamos a fazer adubação de manutenção, e os ciprestes agradeceram".

Voltando as formas, o primeiro ser humano desenhado com cipreste foi o Jeca Tatu, uma homenagem às suas tradições rurais brasileiras. Depois surgiram homens em outros ofícios, casais dançando, crianças de mãos dadas. Mais recentemente, santos e Jesus estão em esculturas frontais à Igreja Matriz. Além dos formatos geométricos clássicos no túnel ou nas cercas-vivas de contorno da praça, há inúmeros animais ali representados, até um centauro da mitologia grega, afinal a imaginação do seu Fridolino não tem barreiras culturais. Segundo ele, a peça mais difícil de manter é a "junta de bois", pois há vários ciprestes envolvidos. Para cada pata de boi e para cada pé do homem foi plantado um cipreste. Outra dificuldade advém do fato que o cipreste não tolera sombra, então diz ele: "é impossível criar figuras que exijam algo embaixo", como já sugeriram um terneiro mamando na vaca. Mesmo aposentado, ele continua criando e praticando. No seu procedimento de trabalho, primeiro ele estuda a forma do desenho desejado, desenha várias versões no papel e imagina como começar a poda em cima da árvore escolhida. Por exemplo, em uma de suas últimas criações, ele desenhou um agricultor semeando com uma antiga semeadora, mostrou o projeto para o pessoal da prefeitura. Com a idéia aprovada ele a implementou em três exemplares de cipreste que já estavam plantados há anos na praça.

Como ele habita em frente à praça, ele vê sua criação diariamente e ainda pode orientar seu sucessor, o seu Altevir, que segundo ele "ele é muito bom no que faz e ainda bem que mantêm tudo direitinho! ... mas infelizmente ainda não ousa criar...". Isso ele disse em 2004. Hoje, em 2013, seu Altevir já cria e muito bem. Percebe-se ali a grande responsabilidade de um discípulo de um mestre destes. Como ele sabe que a dinâmica nas prefeituras é sempre demorada, seu maior desejo é que se priorizasse a beleza das praças e dos jardins nas cidades, contratando e treinando jardineiros: "gostaria que as prefeituras se engajassem com a jardinagem, pois isto é atração turística, chama a atenção e deixa o município bonito, as pessoas ficam curiosas pra conhecer. Eu, por exemplo, visitei o norte e vi quantas espécies bonitas de árvores tem por lá. Imagina o que se pode fazer com elas em topiaria! Aqui não se utilizam estas espécies, pois o frio dos nossos invernos castiga demais." Em 2004, ele continuava ensinando e praticando na região toda, desde Santo Cristo até Gentil, Marau e Taquarussu. E está consciente que sua ousadia na criação de formas já está sendo copiada Brasil afora (a praça apareceu no inicio dos anos 2000 como uma das 1001 maravilhas do Brasil no Fantástico, por exemplo) e fica feliz por isso, pois através das plantas "gostaria de ser lembrado como um difusor de beleza e de emoções", sonho de todo paisagista e jardineiro.

\section{História da mãe dos jardins ${ }^{(5)}$ :}

Para dona Delci tudo começou naquela palestra de paisagismo em microbacia, entre mates compartilhados, lá em junho de 1998. Ela diz: "Me lembro muito bem Cláudia quando você perguntou na palestra pra nós: - Imaginam o que é paisagismo? Alguém tem uma idéia? - E ninguém sabia, ninguém respondeu. E você disse: "um cemitério é paisagismo..." ... Nossa !! ... daí eu entendi... e daí eu achei o que fazer da minha vida!!" Houve uma conversa no almoço, pausa entre palestras e fiquei preocupada com essa senhora. A extensionista Rose (em agosto de 2012) lembrou-me que eu lhe disse "Rose, se gruda na dona Delci! Não a deixe sozinha!”, e ainda:

\footnotetext{
(4) Entrevista com senhor Fridolino Schmidt em 2004.

${ }^{(5)}$ Essas informações foram transcritas da entrevista coletiva de Delci Gnich e da extensionista Rosmari Munerolli (19 de agosto de 2012)
} 
"Delci é a mãe dos jardins, ela incentivava, ligava... sempre acompanhando tudo. A Claudia conseguiu as estudantes interessadas em catalogar as plantas do jardim dela (duas em 2006, se hospedaram na dona Delci) e as plantas da praça em topiaria (mais duas em 2007) e pra ajudar, eu as albergava lá em casa. O prefeito da época ajudava pagando o almoço. É uma rede de doação e entre - ajuda, senão não funciona. Acredito que pra dar certo mesmo, a integração é entre pessoas, e não entre instituições..." (Rose, 2012) ${ }^{(6)}$.

Em função do excesso de atividades e de minha mal compreensão do descompasso existente, parei de levar os alunos na visita aos jardins quando houve uma ruptura do trabalho desta extensionista da Emater neste projeto, em função da troca de partidos e prioridades na administração municipal. Até que dona Delci me lembrou durante a feira Expodireto de 2011: "não nos castiguem, não é nossa culpa, Claudia, nós precisamos de vocês!" Enfim entendi que quando houve troca de administrações, a dona Delci quase desistiu do processo pela desmotivação do grupo. Sentia-se excluída e de certa forma anulada... Pareciam boicotes, inclusive meus. Lamento a injustiça que eu estava causando de não ter priorizado continuar as visitas com os alunos da UPF. Na época, a senhora Rovena se desmotivou e saiu. No meio dessa fase de ajustes, Delci acreditou mais na atividade que ela criou e menos na incompreensão de agentes externos. Não desmotivou: "Eu não faço a coisa pra aparecer. Eu faço por merecer. Sempre corri atrás disso e lutei para que isso tudo existisse." Segundo ela, ainda guarda o ofício da Emater de junho de 1998 convidando-a para a palestra sobre paisagismo na microbacia. Quando a revi em 2006, pela primeira vez após 1998, ela disse como sempre, para os turistas das excursões que foi uma palestra de paisagismo que a tirou da depressão. E que eu era responsável por isso. Fiquei tão emocionada ao escutála falar isso a primeira vez, que choramos nós duas, mas imediatamente lembrei-lhe, na frente de meus alunos, que foi só ela que fez o esforço. Claro que fiquei contente e satisfeita, pois feito bem meu trabalho. Mas não só com dados técnicos, coloquei meu coração e meu humanismo naquela ação, como sempre faço. Mas se fui boa técnica, é importante realçar que lá em 1998, eu como técnica, naquela palestra, provavelmente apenas coloquei um espelho na frente dela... e ela se viu nele, viu suas potencialidades, seu amor pela vida e pelas plantas. Após aquele dia de formação eu fui embora. Parti para fazer doutorado no exterior. Ela voltou pra casa, em paz, e não tomou mais antidepressivo faixa preta, mas foi por puro mérito dela. No dia seguinte já acordava cedo novamente para cuidar das plantas, dos passarinhos e do jardim... Estava conectada de novo com seu mundo, com sua terra, através de seu jardim. Desde 2006, desse nosso segundo reencontro, ela se sentiu aliviada e ao menos parou de dizer aos turistas nas excursões.que alguém fora dela foi responsável por ela sair da depressão. Assim são os habitantes paisagistas... eles se encontram na paisagem, mas ainda não se reconhecem necessariamente como tal.
"Cada canteiro tem sua história..."(7). Como é difícil de compreender e respeitar isso. Mas é importante achar sempre o meio termo. Na antiga casa de dona Delci, lá no Barro Preto, no interior de Victor Graeff, agora orgulhosamente herdada por sua filha Anegrid, está tudo diferente do que ela fez. Mas foi uma opção que segundo ela, é a melhor para toda família. Mesmo se fica magoada e dengosa com as mudanças, ela não se mete, pois "sogra é um estorvo" e não precisa ter briga na família. Um exemplo foi o "Cantinho do Inter" (em homenagem ao time Internacional, de Porto Alegre) que os funcionários da filha alertaram-na que ele ia acabar... E mudou mesmo, saiu a coleção de gérberas e outras vivazes e está atualmente com grama. "Doeu... Mas ficou bonito! Tenho que respeitar". O que ela está aprendendo é se desprender, se desapegar para poder voar mais alto. Por isso recomeçar jardim numa nova moradia faz parte da lição de vida que ela quer nos dar.

Sim, dona Delci funciona como um belo mofo no bom pão. Claro, no bom sentido... onde ela chega ela contamina todos! Foi morar no município vizinho, Ernestina, e lá recomeçou seu novo jardim. Como um novo filho. E por incrível que pareça, a vizinhança toda está com jardins bonitos. Sua irmã que mora ao lado, é proprietária de uma floricultura. Teve auxílio da dona Delci e já aumentou a clientela com muito mais opções de plantas. Dona Delci chega e realmente faz a diferença, faz mudas e testa tudo o que pode. Só não anota. O resultado de seu empirismo aparece nas formas de seus jardins. São os seres vivos que melhor se adaptaram que ficaram, dando o ar de sua graça.

No projeto coletivo do roteiro dos jardins houve pequenos atropelos e alguns poucos mal-entendidos. Mas como o mérito é de todas as jardinistas, elas mantiveramse unidas com altivez. Mas infelizmente, às vezes a ideia de quem é o criador de uma obra coletiva envaidece e às vezes entristece outros que não são tão lembrados ou tão citados. Sempre se lida com egos humanos. No caso do habitante paisagista, ele faz a idéia dar certo pois ele é o agente. Apoiado pelas estruturas administrativas, de preferência. Mas se ele, esse simples morador, habitante, não quiser ou não aceitar um projeto imposto e pouco útil, não haverá resultado positivo nenhum. Isso é difícil de ser compreendido pelos que fazem da política um meio de vida e de aparecer na mídia. Reforço a importância de tudo anotar para criar verdadeiros arquivos (não relatórios parciais), garantindo os arquivos históricos de amanhã. No caso do restante do grupo das jardinistas, também pode ter incomodado o fato da líder aparecer mais vezes que as restantes do grupo. Dona Delci até já retirou seu jardim do roteiro (lembrem-se, agora é o jardim de Anegrid), mas não saiu do roteiro, acompanha as excursões como guia e animadora. Canta, ri, deixa todos à vontade. Quer que se encantem com o que ela descobriu nessas terras. Valorizar líderes reais é manter o vínculo com a história, para que a ideia permaneça no futuro.

Assim, um habitante paisagista sobrevive às mudanças das vontades políticas e conjunturais de seu tempo. Às mudanças de prefeituras, de partidos e de técnicos.

\footnotetext{
(6) "Rose do Mormaço, sempre de Victor", 19/08/2012. É como ela se define.

(7) "Rose do Mormaço, sempre de Victor, 19/08/2012".
} 
Embora todos administradores queiram mostrar serviço, a maioria comete uma tabula rasa, querer começar do zero, desconsiderando tudo o que já tenha sido construído.E professores de universidade também mudam de opinião e se mudam... Mas o habitante permanece, com suas raízes vigorosas. Ainda bem.

No ano de 2012, acabado o descompasso temporário, quando as forças administrativas e a associação das jardinistas voltaram a pensar juntas novamente, houve o apoio para participarem de workshops de turismo na capital. Sentiram-se realizadas, por perceberem que tinham um bom roteiro, mesmo ainda com dificuldades (faltam banheiros etc.). Este problema só não era maior porque elas sempre colocaram os banheiros das casas à disposição, e isso teve sempre uma boa repercussão. Sensibilizava os turistas das cidades maiores (pois eles diziam que nem eles não deixavam estranhos usarem seus banheiros) para a compaixão e para a simplicidade e limpeza do acolhimento. Foram percepções acima, colhidas ao longo das visitas nos últimos anos (elas mantêm livros de assinaturas das visitas), que mantiveram-nas com autoestima elevada. E deram a motivação para continuarem se doando aos jardins, malgrado os empecilhos e dificuldades. Enfim, a autoestima foi sempre regada pela boa receptividade dos turistas. $\mathrm{O}$ olhar estrangeiro ajuda a gente a ver como estamos, o recuo permite ver a paisagem...

Em 2012, participaram também de um evento de troca de sementes crioulas em Tenente Portela, com o apoio da Emater. Teve sete oficinas e dona Delci levou 18 espécies (tomate arbóreo, moranga estrelada, girassol duplo, amendoim malhado... que ninguém conhecia) e os agradecidos lhes ofertaram quatro espécies. Um tipo de milho que ela não sabe como se usa nem pra que serve. Inquieta, procurou ajuda mas ainda não teve a resposta a essa questão. Mas pra não perder tempo, já distribuiu bastante semente, para todos irem plantando. Quando ela souber pra que serve já existirá bastante produção. Assim pensa dona Delci: compartilhar e crescer juntos. Não disperdiçando o tempo das sementes.

\section{As bênçãos dos jardins ordinários}

No roteiro, a história de comer é fundamental. Os lanches sempre foram fantásticos. E seduziam os alunos que participavam das visitas. Tanto é importante que a Associação das jardinistas publicou um livro com 35 receitas $^{(8)}$, com apoio da Emater e Prefeitura Municipal. Para isso é preciso ter diversidade de alimentos e de preferência produzidos de maneira sustentável. Para EHLERS (1999), citando o trabalho em sistemas de produção orgânica, não há 'pacotes' como na 'revolução verde'; a educação é o melhor insumo para a conscientização; cada agroecossistema é único e exige soluções diferenciadas, mas há em comum a integração com animais; o sistema rotacional e de diversificação; a pesquisa com enfoque sistêmico; e a adoção de políticas públicas que promovam a agricultura familiar. Este contato com a terra pelas habitantes paisagistas faz crescer seu conhecimento sobre a natureza. E cada vez mais, este conhecimento tem sido democratizado para pequenas iniciativas ou pequenas áreas, como é o caso das hortas-jardins orgânicas (ESCRIVÁ, 2010). Assim a autora define a valoração estética da horta, acrescentando-lhe o substantivo jardim, embora horticultura contemple jardim em sua origem etimológica (PETRY, 2004).

Como eternas agriculturas, essas jardinistas valorizam técnicas sustentáveis e uso de grande diversidade de espécies rústicas. No mesmo senso de aliar ciência e arte com princípios ecológicos, HITCHMOUGH (2010) realça alguns critérios ecológicos importantes na horticultura urbana atualmente praticada e YOUNIS et. al (2010) demonstram uma boa aceitação dos usuários de parques, da implantação de espécies herbáceas selvagens e rústicas. OSBORNE et al. (2007) comprovaram na Inglaterra a importância da presença de jardins urbanos para a sobrevivência de insetos polinizadores e conseqüentemente para a preservação da biodiversidade. As jardinistas buscam critérios para aumentar a fauna e a flora. Mas necessitam algumas vezes de ajuda técnica para discernir o que é um bom critério.

Morando no meio rural, elas vislumbram belas cenas no cotidiano. Se a paisagem é longe, o jardim é o filtro da paisagem, ele é próximo, cercado e todos nos sentimos seguros nele. A cerca define o espaço privado e garante que estamos em casa. Ele é tão cuidado e precioso, que o jardineiro ordinário utiliza a medida do are (CAUQUELIN, 2005). Em 1984, a antropologa Françoise Dubost escreveu: "Nos jardins dos antigos no meio rural, flores e legumes se misturam num modo tradicional, seis fileiras de alhoporó, uma de zínias, um canteiro de couves e uma touceira de dálias" (DUBOST, 1997). E continuam assim, só muda as quantidades. Por isso a jardinista rural aprende a lidar com limites, manter a escala humana na paisagem rural, restringindo a atuar no seu jardim de forma intensa.

No jardim ordinário, tem o jardim secreto, ou filosófico, que é o centro do jardim, ou melhor, o objetivo maior da visita ao jardim (CAUQUELIN, 2005). Segundo esta filósofa, estes jardins possuem cercas, pontos de vista, centro, aléias e bordaduras, cabanas, cadeiras e bancos, vasos e estátuas, relação ao tempo e ao passeio, descrição e récitos, construções e casas, pórticos e varandas. No caso dos jardins das nossas habitantes paisagistas agricultoras, o jardim filosófico ou o jardim secreto é a sala da confraternização, o quiosque com a mesa farta de excelente e saborosa comida. Ao mesmo tempo, compartilha visceral e social. O restante também existe, mas é menos paparicado.

E esse jardim saudável leva à um corpo saudável (SERBAN-SCHREIBER, 2008). Na alimentação, pululam idéias como comer para viver, comer com prazer, comese melhor em casa, se sentindo bem no próprio corpo, com aplicação de indulgências que exigem redução para compensar (GUILIANO, 2005). Para esta autora, fazer as pazes entre Narciso e Pantagruel é uma questão de equilíbrio, e valorizar os rituais da mesa, é necessário para hoje honrar as tradições. Sendo comida (e não produtos artificiais) já é o melhor caminho para a saúde, não sendo em excesso e de preferência vegetais, então fica perfeito (POLLAN, 2010). E de preferência resgatar a beleza 
saudável da horta, pois mais que nunca, a horta biodiversa de hoje é muito linda (ESCRIVÁ, 2010), além de poder ser rentável (JEWTUSZYK e SACKEWITZ, 2006) e extremamente autossuficiente (KINGSOLVER, 2008).

Todos os jardins rurais tem espelho d'água. Ou açudes. E estares. Se o espelho d'água "acrescenta estrelas ao céu" (sidera addiere caelo", Jardim de Erasmo), e o estar significa "onde estão os amigos, está a riqueza" (ubi amici, ibi opes) (CAUQUELIN, 2005), o jardim ordinário exige paciência, tentativas e retomadas perpetuamente. Além do espaço para o ser humano, o jardineiro se ocupa do "ser vivo" (CLEMENT, 2012). Ele cria uma paisagem ao compor o jardim. E se o paisagista organiza a estética mutante do jardim (ou da paisagem), o jardineiro interpreta no cotidiano as "invenções" da vida, é um ilusionista. Os jardins de dona Delci sempre me lembram obras ilusionistas, são fascinantes em criar expectativas e emoções. Se para Clement (2012), o jardim está no jardineiro e existe pela jardinagem, ele deve ser único pois é uma expressão de um desejo, que muda no tempo e entre pessoas. Sendo o jardim uma fábrica de paisagens, ele porta nele um sonho de sociedade (CLEMENT, 2012, p.28), é um lugar privilegiado do futuro, um território mental da esperança. E serão tantos jardins ordinários, mas autênticos, quantos habitantes paisagistas existirem.É a pura magia da multiplicação de sentidos.

Não basta apenas ser belo e lúdico. Seu sentido pode ir além, buscar a sustentabilidade. Para Clément (2012), o jardineiro precisa de um assistente talentoso e sonhador: um novo economista (economizar significa tomar cuidado e não se endividar) que busca o equilíbrio na entrada e na saída de energia; e que atenta para a localização das trocas. Fazer "com" e o menos possível "contra”. Já em 1973, o economista Schumacher atentava para a diversidade: "Se beleza é o esplendor da verdade", a agricultura só poderá cumprir a sua segunda tarefa (humanizar e enobrecer o habitat mais amplo do homem) se apegar-se fiel e assiduamente às verdades reveladas pelos processos vitais da natureza. Uma delas é a lei do retorno; outra é a diversificação, uma terceira é a descentralização. Hoje o localismo promove a circulação de alimentos produzidos em até $150 \mathrm{~km}$. Na França, a venda direta e o circuito curto já são responsáveis por mais de $20 \%$ das vendas de produtos rurais.

Esta paisagem local tem uma força, um genius loci, uma história vernacular (JACKSON, 2003), sendo estas paisagens o pilar para as gerações futuras (ANTROP, 2005). Inúmeros movimentos sociais altermondialistes (que pregam a visão global, mas com ação local) criaram vários movimentos: slow food; sementes da terra; terra madre, localismo, etc. baseados em questões fundamentais. Para Caporal e Costabeber (2002), as seis dimensões da sustentabilidade são: ecológica, econômica, social, cultural, política e ética É preciso retornar ao tamanho atual do homem. O homem é pequeno e, por conseguinte, o que é pequeno bonito é (SCHUMACHER, 1973). São exemplos de habitantes paisagistas humildes e fortes os mais duradouros.

Sonhar é como olhar para dentro de nós mesmos, e assim percebermos nossas consciências, que em seu âmago habita Deus (CANOVAS, 2010). Às vezes o projetista pode pecar ao projetar meras cenografias apelidadas de "clean", fazendo esquecer que a proposta é devolver a paisagem perdida (CANOVAS, 2010). Para SCHUMACHER (1973) a força das pessoas comuns, que hoje propendem a sentirse de todo impotentes, não está em iniciar novas linhas de ação, mas em levar sua solidariedade e apoio aos grupos minoritários que já as iniciaram. Por isso todas as iniciativas que partem da comunidade são bem sucedidas se apoiadas corretamente, como é o caso destas jardinistas agricultoras.

Citando as bem-aventuranças, SCHUMACHER (1973) considera que elas podem significar para nós, que somos pobres (não somos semi-deuses); que temos muito com que nos entristecer, e não estamos ingressando numa era de ouro. "Precisamos de um enfoque suave, um espírito de não-violência, e saber que a beleza está no que é pequeno. Temos de preocupar-nos com a justiça e fazer com que o direito prevaleça. E tudo isso, somente isso, pode habilitarnos a sermos pacíficos" (SCHUMACHER, 1973, p.139). É na paz conquistada no seu micro território que o habitante paisagista compartilha sua felicidade de viver.

Onde pessoas simples veriam seres da natureza, homens de espírito mais elevado apreendem o que as paisagens têm de mais sutil, seu aspecto sublime, considerando-as locais de manifestação divina que lhes desperta estados de adoração (DELPHIM, 2010). Um habitante paisagista consegue sentir as duas coisas. Pois o habitante paisagista é crente, a crença traz o visual através da lenda, e não fisicamente (CAUQUELIN, 2005).

Encontrar um sentido mais profundo na nossa comunidade, além da nossa família imediata, vai nos fazer alcançar a verdadeira paz interior, tendo o sentimento de encontrar energia naquilo que dá um sentido à própria vida (SERBAN-SCHREIBER, 2003; LENOIR, 2010). Para evitar conflitos e violência, é importante estabelecer um compromisso: encontrar uma solução aceitável para os dois (negociarem?) onde cada um desiste de algo pelo bem comum. É um bom meio para construir a paz duradoura (SEMELIN, 2000). Muitas vezes há uma pessoa que nos ajuda a chegar lá (e que bom contar com elas!), e este pode ser um técnico. SEMELIN (2000) propõem cinco princípios de ação não-violenta (a eficácia depende de nossa a habilidade em aplicá-los e das reações do nosso adversário): 1) Saber quais objetivos precisos se quer chegar; 2) Lutar junto com outros para se fazer escutar (criar a força do número); 3) Encontrar uma boa idéia de ação pela qual o grupo mostra sua força, mas sem violência; 4) Utilizar a força da palavra (explicar e argumentar sua ação para se fazer compreender); 5) Continuar não-violento apesar das eventuais provocações. Foi na doçura fazendo aproximadamente isto, que estas mulheres agricultoras conquistaram o terreno de suas casas numas terras agrícolas de lavouras e partiram como jardinistas para conquistar os corações dos visitantes vindos dos mais variados locais.

Em 1998, os estados da ONU declararam os anos 20002010 como o "decênio da cultura da paz e da não-violência para as crianças do mundo" estimulando: a não violência em todos os sentidos; a compartilhar seu tempo e seus recursos materiais cultivando a generosidade a fim de terminar a exclusão, a injustiça, e a opressão política e econômica; defender a liberdade de expressão e a diversidade cultural privilegiando sempre a escuta e o diálogo (SEMELIN, 
2000). As jardinistas de Victor Graeff estão fazendo cada vez sua parte nesse processo.

Há 2.400 anos atrás, o chinês Lao Tsé no livro do TAO descreve sobre a beleza e o desapego, e parece que habitantes paisagistas mais evoluídos já compreenderam isso:

"No mundo cada um decide a beleza / e isto se torna feio./ No mundo cada um decide do bem/ E aquilo se torna mal. // O ser e o vazio se engendram / Um ao outro. / Fácil e difícil se completam / Longo e curto se definem/ Alto e baixo se encontram / Um ao outro / Voz e sons combinam / antes e após se misturam. // Assim o sábio, do não-agir / Pratica a obra / E ensina sem palavra.// Multitudes de seres aparecem / que ele não rejeita. / Ele cria sem possuir./ Age sem nada esperar / Não se apega à suas obras. // E neste abandono/ Não permanece abandonado". (Tseu, 1984) $)^{(9)}$.

Para o Dalai-Lama, o mais chocante nas sociedades ocidentais é a falta de pertencimento (appartenance) dos indivíduos à uma comunidade, ou entre vizinhos. Isso é surpreendente para um tibetano, que sempre vai buscar conhecer (e saber o nome) seu vizinho. Para eles, tem que ter um sentimento relacional, uma ancoragem emocional e afetiva. Ter com quem compartilhar seus problemas (DALAI-LAMA e CUTLER, 2011), estar compondo um tecido coletivo e transformar a consciência em ação. Primeiro conhecer o problema, e depois como tudo é questão de boa vontade, através da consciência de pertencer a um mundo maior, a família, a comunidade. Onde se vá, não se escapa à coletividade. Mas começa por nós, por mim, eu. Estender a mão ao outro, independente do efeito esmagador da conjuntura da crise mundial. O Dalai-Lama faz uma crítica terrível à televisão 'reality' que prega o individualismo acima da coletividade. DONADIEU (2006) lembra da força da sociedade paisagista, que consciente e organizada, demanda por espaços de compartilha e de bemestar social. E ajuda o mundo social a melhor evoluir.

A nós, como técnicos, como agentes, de garantir a ligação entre espaço privado e espaço público... guardar a individualidade num pequeno espaço, o jardim, deixando-o mais autêntico e singular, mas estarmos conscientes que ao torná-lo de acesso público, com o turismo, ele se globaliza e se humaniza, solidariza intenções e sonhos. Tenho como metas voltar com dona Delci em cada jardim, entrevistar cada agricultora jardinista para saber de seus anseios, projetos e realizações pessoais através do jardim. Com elas criar um dossiê de cada jardim, englobando custos, memorial botânico, explicação funcional e simbólica da escolha de cada planta; ... ou "Inventário florístico da rota dos jardins" (sugestão da Anegrid). Mais um grãozinho foi plantado, em 28 de junho de 2012 quando dei de presente um caderno para cada uma anotar o que considerava importante... Um dia espero ter a honra de estudá-los.
Se o governo deve agir na moderação (TSEU, 1984) e na responsabilidade global, nós, seus técnicos em ação devemos garantir a manifestação das motivações individuais, pois sem estas, não há um processo coletivo de turismo com sucesso, valorizando o ineditismo e o localismo. E vice e versa, o fato dos habitantes paisagistas poderem se expressar autenticamente alimenta corretamente a autoestima. Processo é um caminho a ser percorrido e sendo assim, há constantes reavaliações e retomada de decisões. É artifício dinâmico, como a própria vida. Sempre surgem expressões de uma cultura jardinista e paisagista nos jardins privados, com o artifício e o natural se complementando, e enriquecendo de sentido o imaginário da vida cotidiana. O caso destas habitantes paisagistas, jardinistas rurais, nos demonstra que o principal objetivo para elas foi alcançado: permanecer na zona rural com qualidade de vida, com distinção e orgulho por sentirem-se parte de um modelo de vida por elas construído, digno de ser visitado.

A seguir dois depoimentos de técnicas instrutoras.

1) "Victor Graeff uma historia de amor e cumplicidade pelas plantas: Quando conheci Victor inicialmente com aquela praça maravilhosa percebi que existia algo de diferente naquela cidadezinha. Ao ministrar o primeiro curso de Jardinagem do SENAR em agosto de 2004, a surpresa foi com o grupo, pois as alunas tinham um conhecimento inicial sobre plantas ornamentais e foi bastante produtivo o trabalho durante os três dias. Entre as atividades práticas fizemos as visitas nas propriedades das alunas, uma experiência ímpar pois havia amor brotando de cada folha e flor de seus jardins..... arrematados pela alegria e transparência da satisfação nos arredores de suas casas.

Certamente aprendi muito mais do que ensinei, pois nas entrelinhas das técnicas de cultivo e identificação das plantas ornamentais, conheci a satisfação de um grupo de mulheres que optou pelo belo através de suas intuições e sua dedicação! A lembrança daqueles dias está entre os maiores aprendizados sobre a capacidade do ser humano de preservar, cuidar e criar através das plantas e principalmente na simplicidade do campo.

Em novembro de 2004 ministrei o segundo curso de jardinagem para outro grupo de agricultoras onde fizemos o mesmo roteiro do curso anterior. Estava informalmente criado o roteiro turístico de jardins de Victor Graeff pois à partir daí o grupo de organizou e começou receber excursões que viajavam quilômetros para ver e sentir o efeito da simplicidade expressa em seus jardins e nas mãos das topiarias cuidadosamente criadas na praça por uma única pessoa que deixava seu amor pela sua própria historia misturada à historia da própria cidade transbordar através de suas mãos criando esculturas impares materializando verdadeiras obras de arte.

Hoje Victor serve de exemplo para muitas cidades construírem seus próprios roteiros de jardins mas principalmente exemplo

\footnotetext{
(9) Dans le monde chacun décide du beau / Et cela devient le laid. // Par le monde chacun décide du bien / Et cela devient le mal. // L'être et le vide s'engendrent / L'un l'autre. / Facile et difficile se complètent / Long et court se définissent / Haut et bas se rencontrent / L'un l'autre / Voix et sons s'accordent / Avant et après se mêlent. // Ainsi le sage, du non-agir / Pratique l'oeuvre / Et enseigne sans parole.// Multitudes d'être apparaissent / Qu'il ne rejette pas. / Il crée sans posséder. / Agit sans rien attendre / Ne s'attache pas à ses oeuvres. // Et dans cet abandon / Ne demeure pas abandonné (Tseu, 1984).
} 
de dedicação e amor pelas plantas e de fé que o criador está presente em tanta beleza." (SANDRA RIGO, 2013) ${ }^{(10)}$

2) "Sobre o Caminho das Topiarias, Flores e Aromas e suas componentes, eu posso dizer: que é muito mais que contemplar o belo. Pude sentir que as plantas tem o poder de transformar, sensibilizar, dar ânimo, enfim, sentir que a vida realmente vale a pena quando nos envolvemos com algo tão prazeroso e que assim como um jardim pode ser esculpido a cada dia, nossa vida também pode. Enfim, cada vez que vou para Victor Graeff, sinto que vale a pena acreditar que as plantas são cheias de magia e que esta me contagia".(JUCELAINE VANIN, 2013)(11)

Mas na verdade, o melhor técnico é o que vem a ser dispensável. Aquele cuja mensagem funcionou e não exige mais sua presença técnica. E quisera persistir a saudade de seu abraço fraternal de amigo. Esse é o técnico que almejo ser quando crescer.

\section{CONCLUSÕES}

Autonomia é um caminho de liberação interna do habitante paisagista. Que os técnicos sejam sensíveis o suficiente para auxiliar no desabrochar dessa autonomia. E não interrompam o processo. Com motivação garantida, o caminho/processo continuará a existir no tempo (pois nunca está pronto), garantindo a permanência do habitante paisagista no lugar que gosta. Ou que ele possa expressar com doçura que aprendeu a gostar do lugar que construiu.

\section{AGRADECIMENTOS}

Agricultoras jardinistas e respectivas famílias: Delci Gnich, Anegrid Gnich dos Santos, Ione e Nair Koeche, Sirlei Schröpel, Diva Wollmer; Delci Worst, Rejane Schulz, Adriana Neuhaus e Rovena Ongaratto. Às técnicas (e amigas) Rosmari Munerolli (Emater, RS), Sandra Rigo (Enga. Agra. Senar, RS), Jucelâine Vanin, (Enga. Agra. MS), Francieli Mariani (Enga Agra, MS, doutoranda), Ana Cristina Trentin (Enga Agra); Lidiane Malagutti (Enga Agra). A todos os técnicos que se dedicam a garantir a existência dos habitantes paisagistas.

Agradeço ao CNPq pela bolsa PDE e à UPF pela Licença LPG para estágio pós-doc na França por um ano.

Agradeço à comissão organizadora do Simpósio de Paisagismo pelo grande idealismo e empenho na realização deste evento.

\section{REFERÊNCIAS}

ANTROP, Marc. Why landscapes of the past are important for the future. Landscape and Urban planning. V.70, p.21-34, 2005.

CANOVAS, Raul. O jardim dos sonhos. Revista Brasileira de Horticultura Ornamental, v.16, n.1, p.9-11, 2010. CAPORAL, F. R.; COSTABEBER, J. A. Agroecologia: enfoque científico e estratégico para apoiar o desenvolvimento rural sustentável. EMATER/RS, 2002.

CAUQUELIN, Anne. Petit traité du jardin ordinaire. Paris : Payot \& Rivages. 2005. 206p.

CLÉMENT, Gilles. Jardins, paysage et génie naturel. Paris : Collège de France/Fayard. 2012. 68p.

DALAI-LAMA ; CUTLER, Howard. L'art du bonheur. Paris : Robert Laffont. 1999. 298p.

DALAI-LAMA ; CUTLER, Howard. L'art du bonheur dans un monde incertain. 2011. Cd-rom.

DELPHIM, Carlos Fernando de Moura. O espírito da paisagem. Revista Brasileira de Horticultura Ornamental, v.16, n.1, p.31-33, 2010.

DONADIEU, Pierre. La sociedad paisajista. La Plata: EDULP. 2006. 140p.(Coll. Del Paisaje, série teoria y ensayo, 1)

DUBOST, Françoise. Les jardins ordinaires. Paris : L'Harmattan. 1984, reed. 1997.

EHLERS, Eduardo. Agricultura sustentável. Origens e perspectiva de um novo paradigma. 2ed. Guaíba: Agropecuária. 1999. 157p.

ESCRIVÁ, Maria Gabriela. Huerta-jardin orgânica. Buenos Aires: Albatrós. 2010. 112p. Il.

GUILIANO, Mireille. As mulheres francesas não engordam. 8ed. Rio de Janeiro:Elsevier. 2005. 207p.

HITCHMOUGH, J. Applying an ecological approach: the future of urban horticulture ? Acta Horticulturae, v.881, p.193-200, 2010.

JACKSON, Jonh Brinckerhoff. A la découverte du paysage vernaculaire. Arles : Actes Sud / Versailles : ENSP. 2003. 283p. il.

JEWTUSZYK, Mertha; SACKEWITZ, Ariel. Huerta orgânica rentable. Manual teórico-prático para la produccion ecológica. Buenos Aires: Continente. 2006. $159 \mathrm{p}$.

KINGSOLVER, Barbara. O mundo é o que você come. Uma família prova que você pode comer cuidando da sua saúde e da saúde do planeta. Rio de Janeiro: Nova Fronteira. 2008. 479p.

KOFF, Ana Maria; GOBBI, Luciana Maria. Apresentação. IN: Associação de turismo rural Caminho das topiárias,

(10) Sandra Rigo, Erechim, RS, Brasil, 21 de março de 2013. Instrutora do Senar no primeiro curso para as agricultoras, 2004.

(11) Jucelaine Vanin, Vila Maria, RS, Brasil, 29 de março de 2013. Extensionista da UPF em 2006-2007 e Mestre UPF, Instrutora do Senar, curso em 2012. 
flores e aromas. Caminho das topiarias, flores e aromas: Livro de Receitas. Victor Graeff: Emater/Prefeitura. 2012. $32 \mathrm{p}$.

LENOIR, Frédéric. Petit traité de vie intérieure. Paris : Plon. 2010. 179p.

MENSAGEIRO, Administração municipal visita "Caminho das topiarias, flores e aromas" $\mathbf{O}$ mensageiro, 17/11/2006. p.11.

PEBAYLE, Raymond. Les Brésiliens, pionniers et bâtisseurs. Paris: Flammarion. 1989. 361p. ill.

PETRY, Cláudia. Construction de l'identité des paysages : l'imaginaire des paysages et l'identité territoriale au Sud du Brésil. Doctorat à l'Institut de Géographie, Université Paris I - Panthéon Sorbonne. Paris:UPI, 2003. 340p. il. Thèse (Doctorat en géographie)

PETRY, Cláudia. As muitas origens da horticultura. Horticultura brasileira, v.22, p.1-1, 2004.

PETRY, C.; MUNEROLLI, R.; VANIN, J.; MARIANI, F.; TRENTIN, A.C.; MALAGUTTI, L. A vegetação como patrimônio histórico em Victor Graeff, RS. Mostra de Extensão da UPF. Passo Fundo: Ediupf, 2011. Cd-rom.

POLLAN, Michel. Regras da comida. Um manual da sabedoria alimentar. Rio de Janeiro: Intrínseca. 2010. 160p. SCHUMACHER, E.F. O negócio é ser pequeno (Small is beautiful). Um estudo de economia que leva em conta as pessoas. Rio de Janeiro: Zahar. 1973. 262p.

SÉMELIN, Jacques. La non-violence expliquée à mes filles. Paris : Seuil, 2000. 62p.

SERBAN-SCHREIBER, David. Guérir (le stress, l'anxiété et la dépression sans médicaments ni psychanalyse). Paris : Robert Laffont. 2003. 303p. Il.

SERBAN-SCHREIBER, David. Anticâncer. Prevenir e vencer usando nossas defesas naturais. Rio de Janeiro: Objetiva. 2008. 284p.

SÜSSEKIND, Flora. O Brasil não é longe daqui, O narrador, a viagem. São Paulo : Companhia das Letras. 1990. 318p.

TSEU, Lao. Tao Te King. Le livre de la voie et de la vertu (traduction par Ma Kou. Adaptation et préface par Marc de Smedt). Paris : Albin Michel. 1984. 81p. (coll. Spiritualités vivantes)

YOUNIS, A., RIAZ, A., SALEEM, S., HAMEED, M. Potential use of wild flowers in urban landscape. Acta horticulturae, v.881, p.229-233, 2010. 